\title{
BUDAYA DAN KOMUNIKASI KESEHATAN (STUDI PANDANGAN KESEHATAN PADA MASYARAKAT SUNDA DALAM TRADISI MAKAN LALAPAN)
}

\author{
Retno Hendariningrum \\ Department of Communication Studies \\ Faculty of Social and Political Sciences \\ University of Pembangunan Nasional "Veteran" Yogyakarta \\ Email : retno_hendari@yahoo.com.sg
}

Keywords:

culture,

health communication,

raw vegetable
Culture is communication and communication is culture. Humans learn culture through communication. At the same time communication is a reflection of human culture. Culture is a subjective and objective element created by humans that increased survival of life and resulted in the satisfaction of actors in ecological niches. Cultures are spread among those who can communicate with each other because they have the same language and live at the same time and place. Culture can be learned, passed down from generation to generation. Culture can be learned through fairy tales, legends and myths. It is similar in a view of Sundanese public health on the tradition of eating fresh vegetables. This study aims to describe the public health view of Sundanese in the tradition of eating fresh vegetables. The research method used qualitative approach. Technique of collecting data was done by interview process and literature study. This study was conducted in Sumedang area of West Java. The results show that the healthy view in the tradition of eating fresh vegetables in Sundanese society is passed down from generation to generation and obtained through informal learning process, formal learning, fairy tales, and myths.

\section{Pendahuluan}

Manusia adalah mahluk sosial yaitu suatu mahluk yang saling bergantung kehidupannya satu sama lain, karena manusia tidak bisa hidup sendiri dan selalu membutuhkan pertolongan orang lain. Dengan kata lain manusia hidup bermasyarakat. Manusia juga adalah mahluk berbudaya, yang dikaruniai akal oleh Tuhan yang berbeda dengan binatang. Oleh karena itu, manusia selalu menggunakan akalnya untuk memecahkan masalah yang dihadapinya, termasuk masalah kesehatan. (Notoatmodjo, 2010:65).

Masyarakat dan kebudayaan manusia dimanapun selalu berada dalam keadaan berubah, termasuk masyarakat dengan kebudayaan primitif yang terisolasi dari hubungan masyarakat di luar dunianya sendiri. Perubahan yang terjadi dalam kebudayaan primitif terjadi karena adanya sebab yang yang berasal dari dalam masyarakat dan kebudayaan itu sendiri (Notoatmodjo, 2010:55).

Ada beberapa faktor yang memengaruhi status kesehatan seseorang yaitu lingkungan, baik lingkungan fisik maupun lingkungan sosial, dimana lingkungan sosial ini dapat memengaruhi perilaku seseorang. Manusia sebagai makhluk sosial yang saling ketergantungan satu sama lain dengan lingkungannya sangat membutuhkan pertolongan dari orang lain, dalam memecahkan berbagai masalah individu maupun masalah-masalah sosial yang terjadi dalam lingkungan sekitar manusia. Demikian pula dengan masyarakat Sunda pada masa lalu bahkan hingga sekarang dalam kehidupan sosial mereka dalam memelihara kesehatan.

Budaya erat kaitannya dengan kesehatan. Dari budaya yang kemudian menjadi tradisi turun temurun yaitu tradisi makan lalapan menjadikan orang Sunda dikenal memiliki wajah serta penampilan yang cantik nan rupawan. Kecantikan orang Sunda dipercayai datang dari nenek moyang yang juga merupakan anggota tingkatan atas kerajaan Sunda. Kecantikan para putri-putri keraton Sunda inilah yang dipercaya masih menurun hingga generasi saat ini. Selain karena keturunan, mungkin tidak banyak yang 
tahu bahwa tanah Sunda pun menyimpan rahasia kecantikan sendiri. Ada beberapa kebiasaan orang Sunda yang tanpa disadari menjadikan kulit mereka lebih halus dan membuat tubuh mereka ramping.

Beberapa penelitian sosiologi mengungkap bahwa salah satu kebiasaan mengonsumsi lalapan oleh orang Sunda merupakan budaya, tradisi, dan karakter masyarakat. Hal ini diperkuat oleh letak geografis dan keadaan alam tanah Sunda itu sendiri. Secara geografis Tanah Sunda yang terletak di wilayah Jawa Barat dikelilingi oleh gunung dan pegunungan yang menjadikan tanah Sunda begitu subur. Berbagai jenis tanaman dapat tumbuh dengan baik tanpa banyak masalah di tanah Sunda. Keadaan alam yang dingin khas daerah pegunungan akhirnya membuat orang Sunda berupaya membuat makanan yang mampu meningkatkan rasa panas dalam tubuh. Cabai, yang relatif mudah ditemukan dan mudah tumbuh di tanah Sunda menjadi pilihan untuk diolah menjadi sambal.

Mengonsumsi sambal saja dengan nasi rasanya tidak akan lezat. Akhirnya, orang Sunda memilih lalapan. Lalapan merupakan makanan favorit masyarakat Sunda. Banyak manfaat yang diperoleh dari mengonsumsi lalapan, terutama bagi kesehatan. Budaya makan lalapan orang Sunda ternyata telah ada sejak abad ke-10 Masehi dan disebut dalam Prasasti Taji 901 Masehi. Hal ini diungkapkan oleh peneliti sejarah Fakultas Ilmu Sejarah Universitas Padjadjaran (Unpad) Fadly Rahman. Fadly Rahman mengatakan, bahwa dalam Prasasti Taji tahun 901 Masehi, disebut sebuah nama sajian atau makanan bernama kuluban Sunda yang artinya lalap yang direbut. Menurut Fadly, dengan mengkaji budaya dan sejarah lalapan sebagai upaya mengetahui jejak kuliner Sunda dalam cerita dan citra cita rasanya. Prasasti Taji $901 \mathrm{M}$, berisi daftar hidangan yang sering disajikan pada acara besar, antara lain 57 karung beras, enam ekor kerbau, 100 ayam (www.bintang.com, 2016).

Menurut Fadly Rahman, hidangan lain berupa aneka makanan yang diasinkan, daging asin yang dikeringkan, ikan kaliwas, ikan gurame, bilunlun, telur dan rumahan. Untuk minuman disuguhkan berbagai macam tuak yang berasal dari bunga campaga, bunga pandan dan bunga karamin. Berbagai makanan itu terdapat pada peninggalan sumber-sumber tulisan seperti prasasti dan naskah di Jawa Tengah dan Jawa Timur sejak abad ke-10 menyebut berbagai nama makanan yang hingga kini masih eksis. Nama makanan itu antara lain sambel, pecel, pindang, rarawwan (rawon), rurujak (rujak), dan kurupuk, serta minuman seperti dawet, wajik dan dodol. Kekhasan ini berhubungan erat dengan wacana pencitraan makanan melalui pengakuan budaya etniknya. Bila ditelusuri jejak kultur historisnya, pengakuan khas hidangan etnik tertentu dalam bisnis restoran akan menjadi basis citra cita rasa apa yang mesti dipertahankan (www.bintang.com, 2016).

Budaya makan lalapan dalam tradisi makanan masyarakat Sunda, sebenarnya sejalan dengan budaya makan dalam tradisi modern. Dalam tradisi makan modern dikenal dengan appetizer yaitu makanan pembuka yang biasanya berupa sayuran mentah. Tradisi barat atau modern juga menyebut dengan nama salad. Dalam makanan mentah appetizer atau salad terdapat dressing atau bumbu sebagai pelengkap makanan mentah tersebut, seperti halnya lalapan dan sambal. Di belahan daerah lain di Indonesia juga dikenal makanan sejenis seperti gado-gado, karedok, lotek yang kesemuanya berisi makanan hamper semuanya berupa sayuran dan bumbu. Dari beberapa tayangan media, masyarakat mengetahui bahwa makanan-makanan ini dikenal pula memiliki efek yang baik untuk kesehatan. Selain baik untuk kesehatan, lalapan dipercaya pula membuat kulit halus dan melangsingkan. Karena itu manusia beramai-ramai mengkonsumsi makanan yang berupa sayur-sayuran ini.

Semakin modern semakin banyak terjadi polusi yang memungkinkan makanan-makanan seperti lalapan tersebut tidak bebas dari berbagai zat lain yang membahayakan. Ada bahaya dari pestisida atau residunya yang digunakan petani ketika membudidayakan tanaman lalapan. Di sisi lain dalam budaya modern banyak tersaji makanan instan atau makanan siap saji (junk food) yang kurang kandungan serat, memicu meningkatkan berbagai penyakit degeneratif seperti penyakit jantung koroner, diabetes melitus, hipertensi, stroke, kanker dan lain-lain. Pola makan masyarakat Sunda bisa menjadi salah satu alternatif untuk menyeimbangkan konsumsi makanan sehari-hari.

Berdasarkan penjelasan di atas, penelitian ini bertujuan untuk mendeskripsikan pandangan kesehatan pada masyarakat Sunda dalam budaya makan lalapan.

\section{Kajian Pustaka}

\subsection{Fungsi Budaya}

Budaya terdiri atas elemen-elemen yang tidak terhitung jumlahnya (makanan, tempat tinggal, pekerjaan, pertahanan, kontrol sosial, perlindungan psikologis, keharmonisan sosial, tujuan hidup, dan lain-lain). (Samovar dkk, 2014:29). Inti penting dari budaya adalah pandangan yang bertujuan untuk 
mempermudah hidup dengan "mengajarkan" orang-orang bagaimana cara beradaptasi dengan lingkunganya. Seperti yang Triandis tuliskan, budaya "berperan untuk memperbaiki cara anggota kelompok suatu budaya beradaptasi dengan ekologi tertentu dan hal ini melibatkan pengetahuan yang dibutuhkan orang supaya mereka dapat berperan aktif dalam lingkungan sosialnya. (dalam Samovar dkk, 2014:28). Menurut Sowell (dalam Samovar dkk, 2014:28) budaya ada untuk melayani kebutuhan vital dan praktis manusia-untuk membentuk masyarakat juga untuk memelihara spesies, menurunkan pengetahuan dan pengalaman berharga ke generasi berikutnya, untuk menghemat biaya dan bahaya dari proses pembelajaran semuanya mulai dari kesalahan kecil selama proses coba-coba - sampai kesalahan fatal.

Salah satu karakter penting dari budaya adalah bahwa budaya itu perlu dipelajari. Seperti dikatakan Bates dan Plog (dalam Samovar dkk, 2014:32-33) : apakah kita menghidupi diri dengan menanam ubi rambat atau dengan berburu bianatang buas atau dengan menggembalakan unta dan menanam gandum, apakah kita menjelaskan hujan badai dengan merujuk pada kondisi meteorologis atau dengn anggapan bahwa itu adalah perkelahian para dewa - semuanya itu ditentukan oleh apa yang kita pelajari dalam proses enkulturasi.

Enkulturasi adalah menunjuk pada proses pembelajaran suatu budaya yang total. Lebih spesifik lagi, enkulturasi adalah seperti yang Hoebel dan Frost katakan, "baik kondisi sadar maupun tidak sadar yang terjadi dalam proses tersebut, sebagai individu, anak atau orang dewasa, menerima kompetensi dalam budaya tertentu". Dari bayi suatu kelompok budaya mempelajari pola perilaku dan cara berpikir sampai banyak dari pola ini terinternalisasi dan menjadi kebiasaan. Hal yang special tentang proses pembelajaran ini adalah bahwa bayi sehat yang normal dapat lahir di keluarga manapun di dunia ini serta akan belajar tentang budayanya dan menerima hal itu sebagai miliknya. (Samovar dkk, 2014:33)

\subsection{Manusia dan Lingkungan}

Di dalam kesatuan ekosistem, kedudukan manusia adalah sebagai bagian dari unsur-unsur lain yang tidak mungkin terpisahkan. Karena itu sepertihalnya dengan oragnisme lain, kelangsungan hidup manusia tergantung pula pada kelestarian ekosistem. Karena factor manusia adalah sangat dominan, maka manusia harus dapat menjaga kesersian hubungan timbal balik antara manusia dengan lingkungannya, sehingga keseimbangan ekosistem tidak terganggu. Pengaruh manusia terhadap lingkunganya dapat mengakibatkan tiga bentuk kemungkinan kualitas lingkungannya, yaitu deteriosasi, tetap lestari, dan perbaikan. (Irianto, 2013:340-341)

Manusia hidup di bumi tidak sendirian, tetapi hidup bersama mahluk lain, yaitu hewan, tumbuhan dan jasad renik (mikroba). Mahluk lain itu tidak sekedar kawan hidup bersama secara pasip terhadap manusia, melainkan hidup manusia itu terkait erat kepada mereka. Tanpa mereka manusia tidak dapat hidup. Anggapan bahwa manusia adalah mahluk yang paling berkuasa adalah tidak sepenuhnya benar. Sebaiknya manusia yang harus menyadari bahwa manusia tergantung mereka untuk kelangusngan hidupnya, bukan sebaliknya. (Irianto, 2013:341)

\subsection{Komunikasi Kesehatan}

Mengapa komunikasi sebagai sesuatu yang dilakukan sehari-hari perlu dipelajari? Semua karena terdapat beberapa kegagalan dalam pekerjaan atau karier karena kegagalan dalam berkounikasi. (Mulyana, 2003:3-4) Komunikasi kesehatan secara konseptual adalah hubungan antara "komunikasi" dengan "kesehatan", sehingga konsep komunikasi memberikan peranan pada kata yang mengikutinya. (misalnya komunikasi bisnis, komunikasi cultural, komunikasi gender dsb).

Menurut Northhouse and Northhouse (dalam Notoatmodjo, 2010:147-148) komunikasi kesehatan merupakan bagian dari komunikasi antar manusia yang berfokus pada bagimana seorang individu dalam suatu kelompok/masyarakat menghadapi isu-isu yang berhubungan dengan kesehatan serta berupaya untuk memelihara kesehatnnya. Fokus dalam komunikasi kesehatan adalah "transaksi" spesifik pada isuisu yang berhubungan dengan kesehatan dan factor-faktor yang mempengaruhi transaksi tersebut. Transaksi yang berlangsung antar ahli kesehatan dan antara ahli kesehatan dengan klien merupakan perhatian utama dalam komunikasi kesehatan. Transaksi tersebut berlangsung berlangsung baik "verbal" maupun "non verbal", "lisan" atau "tulisan", personal atau impersonal. Dengan demikian dapat dikatakan bahwa Komunikasi Kesehatan merupakan aplikasi dari konsep dan teori komunikasi dalam transaksi yang berlangsung antar individu/kelompok terhadap isu-isu kesehatan. 
Beberapa deksripsi dari Liliweri (2011:45-48) bisa dikutip untuk menjelaskan definisi komunikasi kesehatan, yaitu: (1). Studi yang mempelajari bagaimana cara menggunakan strategi komunikasi untuk menyebarluaskan informasi kesehatan yang dapat mempengaruhi individu dan komunitas agar mereka dapat membuat keputusan yang tepat berkaitan dengan pengelolaan kesehatan, (2). Studi yang menekankan peranan teori komunikasi yang dapat digunakan dalam penelitian dan praktik yang berkaitan dengan promosi kesehatan dan pemeliharaan kesehatan, (3). Pendidikan kesehatan yakni suatu pendekatan yang menekankan pada usaha mengubah perilaku kesehatan secara luas agar mereka mempunyai kepekaan terhadap masalah kesehatan, dan (4). Proses kemitraan antara para partisipan berdasarkan dialog dua arah yang di dalamnya ada suasana interaktif, ada pertukaran gagasan, ada kesepakatan mengenai kesatuan gagasan mengenai kesehatan, juga merupakan teknik dari pengirim dan penerima untuk memperoleh informasi mengenai kesehatan yang seimbang demi memaharui pemahaman bersama.

\section{Metode Penelitian}

Penelitian ini menggunakan pendekatan kualitatif. Penelitian kualitatif adalah penelitian yang bersifat interpretif (menggunakan penafsiran) yang melibatkan banyak metode, dalam menelaah masalah penelitannya. Penggunakan banyak metode ini sering disebut triangulasi - dimaksudkan agar peneliti memperoleh pemahamn yang komprehensif (holistik) mengenai fenomena yang ia teliti. Sesuai dengan prinsip epistimologis-nya, peneliti kualitatif lazim menelaah hal-hal yang berada dalam lingkungan alamiahnya, berusaha memahami, atau menafsirkan, fenomena berdasarkan makna-makna yang orang berikan kepada hal-hal tersebut. (Denzin dan Lincoln, dalam Mulyana, 2007:4). Secara konvensional metode kualitatif cenderung diasosiakan dengan keinginan peneliti untuk menelaah makna, konteks, dan suatu pendekatan holistik terhadap fenomena. (Hayes dalam Mulyana, 2007:5-6).

Pengujian validitas data dilakukan dengan teknik triangulasi, yaitu pengujian dengan jalan meminta sumber lain sebagai pembanding hasil penelitian dan untuk lebih meyakinkan pernyataan yang ada. Pengujian ini dilakukan melalui wawancara dengan informan dan literatur. Diharapkan hasilnya dapat dijadikan sebagai pembanding hasil penelitian yang ada.

\section{Hasil Penelitian Dan Pembahasan}

Dalam budaya Sunda kombinasi makanan lalapan dan sambal menjadi menu wajib untuk tiap kali makan. Lalapan sendiri adalah sayur-sayuran segar. Begitupun sambal yang harus pedas. Konsumsi sayuran setiap hari bisa menjamin masukan nutrisi dan vitamin yang bagus untuk tubuh dan kulit. Sedangkan, sambal dipercaya mampu berperan memperlancar metabolisme tubuh dalam pembuangan lemak. Tradisi memakan lalapan nggak berhenti hanya pada skala makanan rumahan saja. Saat ini, dengan semakin banyaknya restoran atau rumah makan ala Sunda, tradisi makan lalapan pun terbawa hingga ke seluruh pelosok Indonesia.

Seperti dikatakan oleh salah seorang Sunda Ibu Yayat (65 tahun), bahwa makan lalapan merupakan tradisi sejak kecil hampir di setiap waktu makan selalu tersedia lalapan dan sambal. Bu Yayat yang tinggal dengan suaminya, anak, menantu dan dua cucunya bahkan sampai sekarang masih memiliki tradisi menyediakan lalapan di rumah walaupun menu lain yang dihidangkan mengikuti tradisi modern. Anaknya Desy (30 tahun) demikian pula untuk selalu menyediakan makan dengan lalapan. Cucu-cucunya yang masih sekolah SD dan TK juga terbiasa makan dengan lalapan. Seperti yang Hoebel dan Frost katakan, bahwa dalam enkulturasi baik kondisi sadar maupun tidak sadar yang terjadi dalam proses tersebut, sebagai individu, anak atau orang dewasa, menerima kompetensi dalam budaya tertentu. (Samovar dkk, 2014:33). Dari bayi suatu kelompok budaya mempelajari plaperilaku dan cara berpikir sampai "proses pembelajaran" ini adalah bhwa bayi sehat yang normal dapat lahir di keluarga manapun di dunia ini serta akan belajar tentag budayanya dan menerima hal itu sebagai miliknya.

Bates dan Plog mengatakan bahwa salah satu karakter penting dari budaya adalah bahwa budaya itu perlu dipelajari. Anak cucu dari orang Sunda akan mempelajari tradisi makan dengan lalapan sebagai sesuatu budaya miliknya. Penerus generasi Sunda akan mempelajari apakah mereka makan dengan tradisi lalapan adalah menerima kompetensi dalam budaya itu sebagai miliknya. Menurut Samovar dkk (2014:33) seringkali seseorang banyak mendapatkan pembelajaran informal yang kadang sulit dikenali, biasanya terjadi melalui interaksi, pengamatan, dan imitasi. Pembelajaran informal sering terjadi dalam kehidupan sehari-hari melalui interaksi dalam keluarga, teman, dan masyarakat. Seperti halnya orangtua kita mencium kita dan kita belajar mencium - kepada siapa, kapan, dan di mana. Begitu pula dalam 
konteks pembelajaran tradisi makan lalapan. Generasi penerus masyarakat Sunda akan melakukan pembelajaran melalui interaksi, pengamatan, dan imitasi yaitu bagaimana orang tua menyediakan hidangan makan dengan lalapan sebagai menu yang selalu ada dalam setiap waktu makan. Pada akhirnya generasi penerus masyarakat Sunda melakukan imitasi terhadap apa yang dilakukan oleh orang tuanya.

Selain pembelajaran informal, pengajaran formal tentang budaya juga diterima oleh seseorang yang jauh lebih tersetruktur dan kadang tergantung pada institusi yang berada dalam budaya tersebut, seperti sekolah. Kadang juga sulit membedakan pembelajaran secara informal dan informal . karena budaya memengaruhi seseorang mulai lahir sehingga seseorang jarang menyadari pesan yang diterimanya. Seperti dikatakan Keesing (dalam samovar, 2014:33) bahwa budaya cenderung untuk tidak disadari. Seperti juga dikatakan oleh Edward T. hall dalam The Hidden Dimension. Judul buku dari Hall tersebut dimaksudkan untuk menarik perhatian akan premis penting bahwa keberadaan budaya itu begitu nyata dan pervasive, sehingga kadang tidak kelihatan. Seperti misalnya mengapa seseorang topi baseball di depan umum dsb. Seperti halnya budaya atau tradisi makan lalapan masyarakat Sunda. Kadang-kadang kebisaan ini tidak disadari oleh masyarakat Sunda, sebagai sebuah kebiasaan baik yang bisa mendatangkan kesehatan tubuh untuk selalu mengkonsumsi sayuran.

Dalam konteks budaya makan lalapan oleh masyarakat Sunda yang diwariskan dari generasi ke generasi, Wood dengan jelas mengatakan bahwa terjadi hubungan penting antara budaya dan komunikasi. Bahwa budaya adalah komunikasi, dan komunikasi adalah budaya. Seseorang mempelajari pandaangan dan pola budaya dalam proses komunikasi. Ketika kita berinteraksi dengan orang lain, semuanya menyadarkan tentang nilai, norma, Bahasa, dan budaya kita. (Samovar dkk, 2014:34)

Budaya makan lalapan pada masyarakat Sunda sebenarnya bisa menjadi contoh atau bahkan menginisiasi untuk melakukan gerakan kembali ke alam. Dalam hal ini adalah gerakan makan sayuran. Inisiasi bisa dilakukan melalui pembelajaran informal dan pembelajaran formal seperti halnya pewarisan makan lalapan dari generasi ke generasi. Karena diperlukan peran masyarakat dan media untuk menginformasikan ini.

Pewarisan budaya juga terlihat bagaimana tradisi makan lalapan ini masih menjadi pilihan gaya hidup masyarakat Sunda melalui dongeng dan mitos. Cerita-cerita dongeng dan mitos mengenai kecantikan gadis Sunda karena pola makan yang unik dengan selalu mengkonsumsi sayuran menjadikan gaya hidup makan lalapan menjadi pilihan masyarakat Sunda terutama para gadis. Gaya hidup modern tidak menjadikan pilihan makan dengan lalapan ditinggalkan. Tentunya dalam kehidupan modern, mitos dan dongeng bersinegi dengan pengetahuan hidup sehat makan sayuran mentah menjadikan seseorang memiliki tubuh sehat dan kulit halus.

Lalapan sebagai makanan mentah, memerlukan makanan organik yang lebih sehat. Makanan organik belum sepenuhnya menjadi pilihan masyarakat Sunda. Makanan organik merupakan makanan dari produk nabati tumbuh tanpa menggunakan pestisida buatan, pupuk, atau herbisida. Sementara itu, untuk daging, telur, dan produk susu organik diperoleh dari hewan yang diberi makan dari alam dan tidak diberi hormon atau antibiotik. Makanan alami adalah makanan yang bebas dari bahan sintetis atau buatan atau aditif. Makanan sehat adalah istilah umum yang digunakan, baik untuk makanan alami maupun organik, atau makanan biasa yang melewati sedikit proses pengolahan, seperti tepung gandum utuh.

Tradisi makan lalapan bagi orang Sunda dan kesadaran hidup lebih sehat dengan memilih makanan organik belum sepenuhnya menjadi pilihan sebagian masyarakat Sunda. Seperti dikatakan oleh Ibu Adinda (35 tahun) seorang pengusaha warung makan, untuk menyediakan sayuran terutama untuk lalapan masih dirasakan cukup mahal untuk keperluan warung makannya. Pasar tradisional tidak banyak yang menyediakan bahan makanan organik. Apabila warung makan yang dijualnya menggunakan bahan organik, maka akan berimbas pula pada mahalnya makanan yang akan dijual. Selain juga ketersediaan nya masih sangat sedikit. Namun untuk konsumsi keluarga beberapa sayuran menggunakan bahan makanan organik.

Ketersediaan bahan makanan organik di pasar tradisonal yang masih sedikit belum memungkinkan sebagian besar masyarakat menikmati bahan makanan organik. Jikakalu ada masih banyak yang belum menggunakan sertifikasi sehingga masyarakat belum bisa membedakan apakah bahan organik atau bukan. Selain juga penjual di pasar tradisional tidak menginformasikan bahan makanan yang dijualnya. Makanan organik masih menjadi sesuatu yang ekslusif karena sebagian besar ketersediannya di supermarket-supermaket besar. Makanan organik di supermarket biasanya sudah menggunakan label organik dari lembaga pensertifikasi organik. Hal ini memudahkan masyarakat untuk mengidentifikasi 
mana yang organik dan mana yang bukan. Akan tetapi harganya yang mahal membuat sebagian kecil saja yang bisa menikmati makanan organik ini.

Sebuah penelitian di Garut yang dilakukan oleh Musa Hubeis menunjukkan bahwa Garut sebagi pemasok makanan organik dalam rangka banyaknya permintaan dan adanya kebijakan pemerintah mengenai produk pangan organik, menjadikan tanaman pangan organik sebagai bagian dari green policy (going green) yang terlibat dengan pelestarian/ramah lingkungan, atau gaya hidup baru. Pendukung gaya hidup organik percaya bahwa makanan yang diproduksi dengan cara ini memiliki mutu dan nilai gizi yang lebih tinggi dibandingkan dengan makanan yang diproduksi secara konvensional dengan kimia sintetik sebagai input pertanian. Inovasi ini menunjukkan bahwa terdapat 3 rantai pasok sayuran organik di Jawa Barat, khususnya di daerah Garut. Hasil penelitian memperlihatkan bahwa pertanian di Jawa Barat berupa pertanian konvensional, semi organik dan organik.

Informasi yang kurang layak, menjadikan beberapa informasi mengenai makanan organik kurang diterima dengan baik oleh masyarakat. Banyak yang berpendapat bahwa makanan organik memiliki konsentrasi nutrisi yang lebih tinggi, tapi pendapat itu tidak sepenuhnya benar. Kandungan nutrisi makanan juga sangat bervariasi, tergantung kapan bahan makanan dipanen dan bagaimana cara menyimpan dan proses pengolahannya. Tidak ada bukti yang menunjukkan bahwa makanan organik, alami, atau sehat terasa lebih enak dibandingkan makanan biasa (kecuali jika bahan-bahan tersebut dalam kondisi sangat segar) (www.cnnindonesia.com, 2016).

Rasa makanan dapat ditentukan oleh genetika tanaman, bukan berdasarkan jenis bahan makanan, apakah organik atau biasa. Cara panen dan cara merawat bahan makanan juga memengaruhi rasa. Rasa buah persik atau tomat yang dipetik ketika masih terlalu hijau tidak akan seenak buah yang matang pada pohonnya. Meskipun tidak memengaruhi rasa atau nutrisi, berbagai jenis pupuk memiliki efek pada lingkungan. Banyak orang tidak keberatan untuk membayar lebih untuk makanan organik karena produksinya tidak menyebabkan kerusakan lingkungan akibat penggunaan pestisida dan herbisida. Selain itu, tanaman organik juga menggunakan pupuk kompos yang tidak merusak lingkungan, seperti pupuk buatan. Namun, label "organik" pada bahan makanan belum menjamin makanan bebas dari kontaminasi ketika bahan didistribusikan ke pasar (www.cnnindonesia.com, 2016).

Sebenarnya, gerakan 'kembali ke alam' dengan makanan organik muncul pada tahun 1940an, menanggapi industrialisasi pertanian yang semakin gencar menggunakan pupuk kimia. Seiring berjalannya waktu, pertanian dan makanan organik semakin besar, menyusul kepedulian masyarakat akan gaya hidup sehat. Mendukung gerakan tersebut, kini berbagai negara di dunia menerapkan kebijakan pangan seperti pelabelan sertifikasi organik agar suatu bahan pangan dapat dijual ke konsumen sebagai 'bahan pangan organik', termasuk Indonesia. Tren tersebut di Indonesia juga semakin besar. Masyarakat sudah mulai berminat dan peduli dengan makanan sehat. Hal berkaitan dengan semakin sadarnya masyarakat akan hidup sehat dengan memilih makanan-makanan yang bergizi (http://perpustakaan.bappenas.go.id, 2016).

Berkaitan dengan bahan makanan organik Pemerintah Indonesia memiliki kebijakan melalui Peraturan Peraturan Menteri Pertanian Nomor 64/Permentan/ OT.140/5/2013 mengenai Sistem Pertanian Organik yang menyatakan bahwa sistem manajemen produksi yang holistik untuk meningkatkan dan mengembangkan kesehatan agroekosistem, termasuk keragaman hayati, siklus biologi, dan aktivitas biologi tanah. Pertanian organik menekankan penerapan praktek-praktek manajemen yang lebih mengutamakan penggunaan input dari limbah kegiatan budidaya di lahan, dengan mempertimbangkan daya adaptasi terhadap keadaan/kondisi setempat. Jika memungkinkan hal tersebut dapat dicapai dengan penggunaan budaya, metoda biologi dan mekanik, yang tidak menggunakan bahan sintesis untuk memenuhi kebutuhan khusus dalam sistem.

Orang Sunda yang memiliki budaya menyantap lalapan yaitu bahan makanan mentah akan lebih baik apabila memiliki kesadaran untuk mengkonsumsi lalapan dengan bahan makanan organik. Pola makan masyarakat Sunda bisa menjadi contoh masyarakat lain. Semua gaya hidup untuk lebih sehat ini tentunya perlu sinergi beberapa pihak yaitu masyarakat, pemerintah, dan kelompok kelompok kepentingan untuk menumbuhkan kesadaran hidup sehat kembali ke alam dengan kembali mengkonsumsi makanan organik.

\section{Simpulan}

Tradisi makan lalapan masyarakat Sunda merupakan budaya yang diwariskan dari generasi ke generasi. Pewarisan ini melalui pembelajaran informal, pembelajaran formal, dan melalui mitos dan 
dongeng. Pewarisan ini menjadikan makan dengan lalapan menjadi pilihan gaya hidup sehat sampai sekarang. Makan lalapan dengan memilih makanan organik sebagai salah satu pilihan kembali ke alam untuk menuju gaya hidup yang lebih sehat. Masih sedikitnya informasi kesehatan mengenai makanan organik dan masih sediktinya ketersediaan bahan makanan ini menjadikan pilihan bahana makanan organik masih menjadi sesuatu yang mahal untuk dilakukan. Tradisi makan lalapan bisa menjadi salah satu contoh gaya hidup sehat untuk masyarakat lain. Pemerintah melalaui kebijakan yang dimilikinya bisa melakukan ini. Perlu sinergitas antara pemerintah sebagai penanggung jawab kebijakan, kelompok kepentingan yang peduli, dan masyarakat untuk mewujudkan hal ini.

\section{Daftar Pustaka}

1) Corcoran, Nova. (2013). Communicating Health Strategies for Health Promotion, $2^{\text {nd }}$ Edition, Sage Publication, Los Angeles, London, New Delhi, Singapore, Washington DC.

2) Irianto, Koes. (2013). Ilmu Kesehatan Masyarakat. Bandung: Alfabeta

3) Liliweri, Alo. (2011). Dasar-dasar Komunikasi Kesehatan. Yogyakarta : Pustaka Pelajar.

4) ------- (2007). Metode Penelitian Komunikasi. Bandung : Rosdakarya.

5) Notoatmodjo, Soekirjo (Prof. Dr. SKM, M. Com. H). (2010). Promosi kesehatan Teori \& Aplikasi. Jakarta : PT. Rineka Cipta.

6) ------. (2010). Ilmu Perilaku Kesehatan. Jakarta : PT. Rineka Cipta.

7) Samovar, Larry A, Richard E.Porter, Edwin R McDaniel. (2014). Komunikasi Lintas Budaya. Jakarta : Salemba Humanika

Internet:

8) http://perpustakaan.bappenas.go.id/lontar/file?file=digital/blob/F23703/Pangan\%20Org`anik.htm, diakses tanggal 19 Mei 2016

9) http://www.cnnindonesia.com/gaya-hidup/kembali-ke-alam-lewat-makanan-organik/ diakses tanggal 19 Mei 2016

10) http://www.bintang.com/lifestyle/read/2424698/kenapa-orang-sunda-suka-makan-lalap-inialasannya, diakses tanggal 20 Mei 2016 